\title{
The UK prevalence of hereditary haemorrhagic telangiectasia and its association with sex, socioeconomic status and region of residence: a population-based study
}

\author{
J W Donaldson, ${ }^{1}$ T M McKeever, ${ }^{1}$ I P Hall, ${ }^{2}$ R B Hubbard, ${ }^{1}$ A W Fogarty ${ }^{1}$
}

${ }^{1}$ Division of Epidemiology and Public Health, University of Nottingham, Nottingham, UK ${ }^{2}$ Division of Therapeutics and Molecular Medicine, University of Nottingham, Nottingham, UK

\section{Correspondence to} Dr James Donaldson, Division of Epidemiology \& Public Health, University of Nottingham, Clinical Sciences Building, Nottingham City Hospital, Hucknall Road, Nottingham NG5 1PB, UK; james.donaldson@nottingham. ac.uk

Received 12 April 2013 Revised 24 August 2013 Accepted 9 October 2013 Published Online First 4 November 2013
To cite: Donaldson JW, McKeever TM, Hall IP, et al. Thorax 2014;69:161-167.

\section{ABSTRACT}

Background Hereditary haemorrhagic telangiectasia (HHT) is an autosomal dominant genetic disorder of aberrant blood vessel development characterised by arteriovenous malformations. HHT is associated with significant morbidity due to complications including epistaxis, gastrointestinal bleeding and stroke. We explored the hypothesis that a diagnosis of HHT is associated with sex, socioeconomic status and geographical location.

Methods We used The Health Improvement Network, a longitudinal, computerised general practice database covering $5 \%$ of the UK population to calculate prevalence estimates for HHT stratified by age, sex, socioeconomic status and geographical location.

Results The 2010 UK point prevalence for HHT was $1.06 / 10000$ person years $(95 \% \mathrm{Cl} 0.95$ to 1.17$)$ or 1 in 9400 individuals. The diagnosed prevalence of HHT was significantly higher in women compared with men (adjusted prevalence rate ratio (PRR) 1.53, 95\% Cl 1.24 to 1.88) and in those from the most affluent socioeconomic group compared with the least (adjusted PRR $1.74,95 \% \mathrm{Cl} 1.14$ to 2.64 ). The PRR varied between different regions of the UK, being highest in the South West and lowest in the West Midlands (adjusted PRR for former compared with latter 1.86, $95 \% \mathrm{Cl} 1.61$ to 2.15 ).

Conclusions HHT prevalence is more common in the UK population than previously demonstrated, though this updated figure is still likely to be an underestimate. HHT appears to be significantly under-diagnosed in men, which is likely to reflect their lower rates of consultation with primary care services. There is under-diagnosis in patients from lower socioeconomic groups and a marked variation in the prevalence of diagnosis between different geographical regions across the UK that requires further investigation.

\section{INTRODUCTION}

Hereditary haemorrhagic telangiectasia (HHT) is an autosomal dominant genetic disorder of blood vessel development characterised by mucocutaneous telangiectases and by arteriovenous malformations in solid organs. ${ }^{12}$ HHT is associated with significant morbidity due to bleeding complications such as epistaxis and gastrointestinal haemorrhage and from embolic complications including cerebral abscess and stroke, ${ }^{3}$ the latter often due to pulmonary arteriovenous malformations (PAVMs). ${ }^{4}$ HHT

\section{Key messages}

What is the key question?

- What is the current prevalence of hereditary haemorrhagic telangiectasia (HHT) in the UK and how does it vary with respect to age, sex, socioeconomic status and geographical location?

\section{What is the bottom line?}

- Using a representative UK general practice database we estimate the prevalence of $\mathrm{HHT}$ to be at least $1 / 9500$, which is more common than previously documented in the UK, though still likely to represent an underestimate of the true prevalence.

\section{Why read on?}

- We identify particular under-recognition in the diagnosis of HHT in men and those from less affluent socioeconomic groups, with a significant variation in diagnostic rates between different geographical regions of the UK.

may also be associated with reduced life expectancy. ${ }^{5} 6$

HHT can be identified by clinical or genetic screening of family members of affected individuals but is too often diagnosed as a result of advanced complications of the disease. A recent expert panel recommended screening all possible or confirmed HHT cases for PAVMs. ${ }^{7}$ Population-based epidemiological studies in HHT are the essential first step in understanding and quantifying the burden of disease and informing healthcare planning for this under-recognised condition. There are few data regarding differences in geographical prevalence of HHT in the UK or associations with sex, age and socioeconomic status, and this is important as understanding these relations may increase knowledge of factors that modify development and diagnosis of the disease.

Hence, the aim of this study was to determine, using a representative sample of the UK population obtained via an electronic general practice database, a contemporary prevalence of diagnosed HHT and its association with age, sex, geographical location and deprivation status. 


\section{METHODS}

\section{Study population}

This study utilised an anonymised, computerised, longitudinal general practice database known as The Heath Improvement Network (THIN) which has been validated for epidemiological research. ${ }^{8}{ }^{9}$ The THIN database records a variety of patient clinical and lifestyle data from consultations in primary and secondary care, including medical conditions, symptoms, medications and sociodemographic details. At the time of data extraction (September 2011), THIN covered 5\% of the UK population with 3.46 million patients actively followed prospectively from 440 general practices. ${ }^{10}$

\section{Definition of disease}

We initially identified all recorded diagnoses (by medical Read codes) between the years 2000 and 2010 of HHT (G770.00) and Rendu-Osler-Weber disease (G770.11). Given the high prevalence of HHT in individuals with PAVMs $^{11}$ we also searched for Read codes pertinent to PAVMs (we excluded any individuals previously identified as having Read codes for HHT or Rendu-Osler-Weber disease to prevent double counting). Population denominator values were derived from the annual mid-year populations contributing to THIN. The results presented in this paper are for patients coded as Hereditary HHT (G770.00) or Rendu-Osler-Weber disease (G770.11) only. A repeat analysis of a wider population was conducted, which included all the Read codes listed in table 1.

\section{Statistical methods}

Data for 2010 (the most recent complete data year) were used to calculate a point prevalence for HHT. We stratified our results by sex, age group ( $<15$ years, 15-49 years and 50+ years), geographical location and socioeconomic status. Geographical location was defined by UK health authority areas and socioeconomic status was based on the Townsend index score in quintiles. ${ }^{12}$ Given the relatively small numbers available for analysis by health authority in 2010, we used combined data from 2000 to 2010 to calculate prevalence estimates for HHT between different health authorities in the UK, adjusting for the use of repeated measures (see below). We were able to look for any significant changes in the prevalence of HHT over the 10-year period between 2000 and 2010. Prevalence estimates taken over multiple years were adjusted by direct standardisation to the 2010 THIN population. Random effects modelling (Huber's method) allowed for the non-independent nature of the cases contributing each year to the overall disease prevalence estimate, adjusting the SEs of the final model. We used Poisson regression to compare prevalence rate ratios (PRRs), controlling

Table 1 Prevalent cases identified in 2010 from The Health Improvement Network database summarised by Read code

\begin{tabular}{llr}
\hline Disease & Read code & N \\
\hline Hereditary haemorrhagic telangiectasia & $\mathrm{G} 770.00$ & 342 \\
Osler-Weber-Rendu & $\mathrm{G} 770.11$ & 23 \\
Sub total & & 365 \\
Pulmonary arteriovenous malformation & $\mathrm{P} 736.12$ & 5 \\
Pulmonary arteriovenous fistula & $\mathrm{P} 736.11$ & 6 \\
Pulmonary arteriovenous aneurysm & $\mathrm{P} 736.00$ & 3 \\
Arteriovenous fistula of pulmonary vessels & $\mathrm{G} 420.00$ & 17 \\
Total & & 396 \\
\hline
\end{tabular}

for year, age, sex, Townsend score and health authority. Statistical tests of significance were performed using the likelihood ratio method unless otherwise stated. All analyses were carried out in Stata SE12 (Stata Statistical Software: Stata/SE V.12.0 for Windows; Stata Corporation, College Station, Texas, USA). The research protocol for this study was approved by the THIN Scientific Review Committee.

\section{RESULTS}

We identified a total of 563 individuals diagnosed with HHT/ Rendu-Osler-Weber Disease in the THIN database from the years 2000 to 2010 with 365 cases contributing to the calculated point prevalence in 2010. Table 1 presents the total number of diagnosed cases identified in 2010 stratified by Read code.

\section{Overall prevalence}

The point prevalence of HHT in 2010 was 1.06/10 000 (95\% CI 0.95 to 1.17 ) or $1 / 9400$. In the sensitivity analysis using broader diagnostic criteria (combining all Read codes from table 1) the point prevalence in 2010 increased to $1.15 / 10000$ (95\% CI 1.04 to .26$)$ or $1 / 8700$.

\section{Prevalence by sex and year}

The prevalence of a diagnosis of HHT was strongly related to sex, with a higher prevalence rate in women compared with men for all years between 2000 and 2010 (figure 1). In 2010 the point prevalence in women was $1.29 / 10000$ person years (95\% CI 1.12 to 1.46 ) and for men was $0.82 / 10000$ person years (95\% CI 0.69 to 96 ). After adjusting for age, deprivation status and geographical location, the PRR in 2010 for HHT was higher in women compared with men (PRR 1.59, 95\% CI 1.30 to $1.94, \mathrm{p}<0.0001)$. The prevalence rate for both men and women has remained relatively constant over the last 10 years.

\section{Prevalence by sex and age group}

Prevalent cases from 2010 were grouped into three different age categories $(<15,15-49$ and 50 years and over) and stratified by sex (figure 2). The unadjusted prevalence rate in both sexes was lowest in those aged $<15$ years and highest in the $50+$ age group though the adjusted PRRs across the age groups did not differ significantly ( $p$ test for trend $=0.29$ ) (table 2 ).

\section{Prevalence by deprivation status}

The prevalence of HHT was inversely associated with socioeconomic deprivation (table 2). The crude prevalence rate in the most deprived group (Townsend score: quintile 5) was 0.68 / 10000 (95\% CI 0.43 to 0.93 ) compared with 1.31/10 000 in the least deprived quintile (95\% CI 1.07 to 1.55 ). After adjusting for the effects of age, gender and geographical location, the PRR was higher in those in the least deprived socioeconomic group compared with those in the most deprived group (PRR $1.74,95 \%$ CI 1.14 to $2.64, \mathrm{p}<0.0001$ ).

\section{Prevalence by health authority}

There was substantial variation in estimates of the crude prevalence of HHT across the UK when stratified by health authority over the 10-year period 2000-2010 (figure 3). The adjusted PRR varied almost twofold across the different UK health authority boundaries (PRR 1.86, 95\% CI 1.61 to 2.15 , p < 0.0001 ) with the lowest adjusted prevalence in the West Midlands and the highest prevalence in the South West (table 3). 
Figure 1 The UK prevalence of hereditary haemorrhagic telangiectasia by sex and year (2000-2010) with total prevalent cases tabulated.

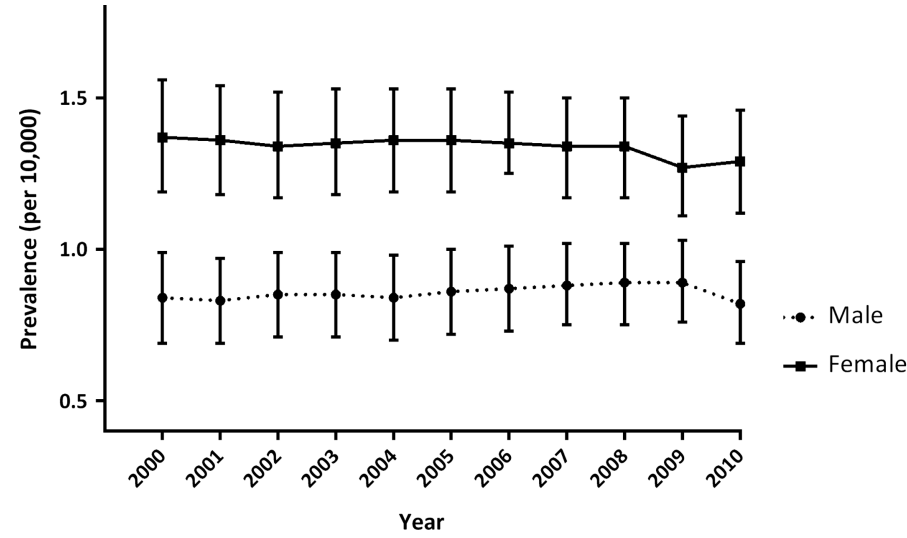

\section{Sensitivity analysis}

The above analyses were repeated to include all Read codes listed in table 1, rather than those for HHT and Rendu-OslerWeber disease alone and revealed no significant differences in qualitative trends of our results or significance values for these trends. There was a slight change in the PRRs calculated for the different health authority areas in the sensitivity analysis, with HHT or PAVMs diagnosed most commonly in Yorkshire rather than the South West (data not shown).

\section{DISCUSSION}

\section{Summary of results}

This is the first study to use a national primary care populationbased database to explore sex, socioeconomic and regional differences in the prevalence of hereditary HHT and provide national prevalence figures for the UK. The 2010 point prevalence for HHT in the UK is 1.06/10 000 (or 1/9400) which has remained relatively stable between 2000 and 2010. The prevalence estimate is higher when Read codes likely to be associated with HHT are included (1/8700) and is higher still if the prevalence in women is considered to be more representative of the population as a whole $(1 / 7800)$. The prevalence increases with age. The diagnosed prevalence ratio of HHT was 59\% higher in women than in men and 74\% higher in those from the least deprived socioeconomic group compared with those in the most deprived group. In addition, we have demonstrated a substantial geographical variation in the diagnosed prevalence of HHT across the UK.

\section{Strengths and weaknesses}

This is the first population-based study of HHT using a primary care database in the UK general population. With a total of 365 HHT prevalent cases identified in 2010, our study sample size is almost four times larger than the last UK estimate undertaken in $1992,{ }^{13}$ is nationally representative and comparable in size with epidemiological studies conducted in other countries. ${ }^{6}{ }^{14} 15 \mathrm{We}$ have been able to stratify our prevalence estimates by sex, age group, deprivation status and geographical location without the risk of bias that may occur either from low response rates (as have been observed in previous surveys of HHT prevalence in the $\mathrm{UK}^{13}$ ) or from case series in specialist centres which may lack a denominator population or represent cases referred for specialist care with potentially more severe disease.

Figure 2 The prevalence of hereditary haemorrhagic telangiectasia by sex and age group in 2010 .

\begin{tabular}{|c|c|c|}
\hline Age group & Male cases & Female cases \\
\hline$<15$ & 15 & 20 \\
\hline $15-49$ & 51 & 90 \\
\hline $50+$ & 75 & 114 \\
\hline
\end{tabular}

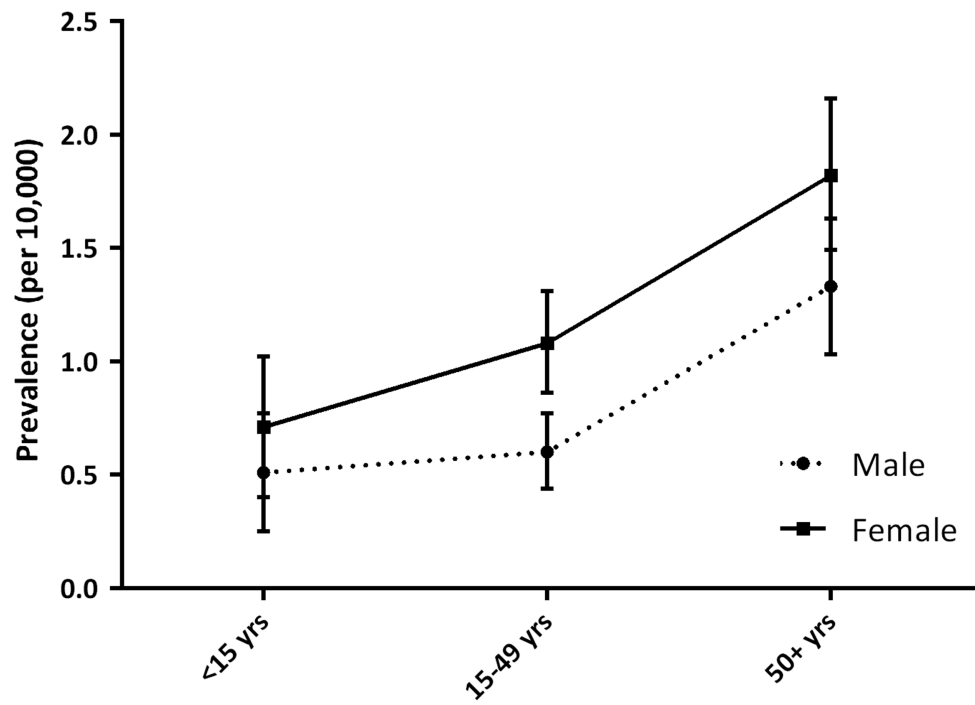

Age Group 
Table 2 Crude prevalence rates and prevalence rate ratios (PRRs) of hereditary haemorrhagic telangiectasia derived from Poisson regression modelling using The Health Improvement Network dataset in 2010.

\begin{tabular}{|c|c|c|c|}
\hline & $\begin{array}{l}\text { Crude prevalence rates }(95 \% \mathrm{Cl}) \\
\text { per } 10000 \text { person-years }\end{array}$ & Crude PRRs $(95 \% \mathrm{Cl})$ & $\begin{array}{l}\text { Mutually adjusted } \\
\text { PRRs }(95 \% \mathrm{Cl})^{*}\end{array}$ \\
\hline \multicolumn{4}{|l|}{ Sex } \\
\hline Male & 0.84 (0.70 to 0.98$)$ & 1.00 & 1.00 \\
\hline Female & 1.28 (1.11 to 1.44 ) & 1.56 (1.25 to 1.95$)$ & $\begin{array}{l}1.53(1.24 \text { to } 1.88) \\
p=0.0001\end{array}$ \\
\hline \multicolumn{4}{|l|}{ Age group } \\
\hline$<15$ years & 0.61 (1.15 to 1.77$)$ & 1.00 & 1.00 \\
\hline $15-50$ years & 0.84 (0.71 to 0.98 ) & 1.39 (0.88 to 2.19$)$ & 1.39 (0.96 to 2.02$)$ \\
\hline$>50$ years & 1.58 (1.35 to 1.81$)$ & 2.62 (1.69 to 4.07$)$ & 2.53 (1.76 to 3.63$)$ \\
\hline & & & $\begin{array}{c}p<0.0001 \\
p=0.29 t\end{array}$ \\
\hline \multicolumn{4}{|l|}{ Townsend score } \\
\hline 1 (least deprived) & 1.31 (1.07 to 1.55$)$ & 1.93 (1.29 to 2.89$)$ & 1.74 (1.14 to 2.64$)$ \\
\hline 2 & 1.05 (0.81 to 1.29 ) & 1.55 (1.701 to 2.38$)$ & 1.36 (0.88 to 2.11$)$ \\
\hline 3 & 1.10 (0.85 to 1.35$)$ & 1.62 (1.03 to 2.55$)$ & 1.50 (0.97 to 2.31 ) \\
\hline 4 & 0.87 (0.63 to 1.10$)$ & 1.28 (0.79 to 2.08 ) & 1.23 (0.78 to 1.94$)$ \\
\hline 5 (most deprived) & $0.68(0.43$ to 0.93$)$ & 1.00 & 1.00 \\
\hline 9 (missing values) & 1.34 (0.77 to 1.91 ) & 1.98 (1.12 to 3.52$)$ & $\begin{array}{l}2.20(1.25 \text { to } 3.88) \\
p=0.026\end{array}$ \\
\hline
\end{tabular}

${ }^{*}$ Adjusted for sex, age group, Townsend score and health authority.

tp-trend across age categories.

There are potential limitations to the study which should be addressed. The first is that of the validity of the HHT diagnoses, which are recorded by general practitioners in the THIN database whilst the clinical diagnosis is generally made in secondary care. In practice, we are reasonably confident that the vast majority of these diagnoses will be correct with the increasing involvement of clinical geneticists in the screening and diagnosis of HHT which should result in more reliable information being conveyed to the primary care practitioner, and hence entered into the database. It seems very unlikely that a primary care practitioner would enter a diagnosis of HHT into the database unless it was supported by correspondence from secondary care. The consistency of our calculated prevalence of HHT with other comparable estimates from previous studies also supports the reliability of our findings. One further limitation that complicates all studies of HHT prevalence at present is the likelihood of undiagnosed individuals with HHT at large in the community. This may explain the higher prevalence of PAVMs as defined by radiological criteria (and by inference, HHT) in patients who were participating in a recent Japanese CT screening program for lung cancer ${ }^{16}$ than we observed in our dataset which did not use this radiological definition of the disease. Diagnosis is often confounded by the heterogeneous clinical presentation of HHT due to its variable genetic penetrance and expressivity. ${ }^{17}$ An average time lag of 25 years separates disease onset and first definite diagnosis. ${ }^{18}$ Hence, our prevalence estimates represent those with diagnosed HHT, and are likely to be lower than the true prevalence defined as all individuals with a mutation compatible with the disease. The fact that our data show the prevalence of the disease has been stable in both sexes over the last decade would suggest that the consistency in coding practice over this period has been maintained.

We used the Townsend score which is a deprivation index based on area as it was not possible to access individual-level deprivation data. This score presumes that individuals living within a geographical area have a similar deprivation status which may not be the case. However, there is evidence to suggest that the Townsend scores calculated at a district level are good proxy measures for individual levels of deprivation. ${ }^{19}$

\section{Interpretation of results}

Reasons for the marked sex difference between the diagnosed prevalence of HHT require careful consideration. One study from the Dutch Antilles showed a 33\% increased prevalence ratio of a 'definite' diagnosis of HHT in women compared with men (using the Curacao criteria), ${ }^{15}$ and a recent US paper found a female:male ratio of 1.54 , with HHT being diagnosed more commonly in women. ${ }^{20}$ Other studies have reported a more balanced distribution between sexes. ${ }^{14}{ }^{17}$ Given HHT is an autosomal dominant disorder, the offspring of affected individuals will have a 50\% chance of inheriting a mutation and this should not per se be associated with a sex bias. Our data show a significant difference in diagnosis of HHT in women compared with men, which appears to be greatest between the ages of 15 and 49. One possible explanation for this observation is that the higher diagnosed prevalence of HHT in women we observed is due to a difference in access to healthcare resources. Women have significantly higher rates of consultation with primary care providers during the ages of 15-70 years with many consultations due to issues surrounding contraception, pregnancy and childcare, and this may explain an increased ascertainment of symptomatic women with HHT. ${ }^{21} 22$ A possible alternative explanation for the disparity between sexes may be that the expression of the HHT phenotype is more common in women with the gene mutation. Little is known about the role of other genetic factors (such as moderator genes) or environmental factors that may modify the HHT phenotype but there is limited evidence that symptoms such as epistaxis may be amenable to treatment via manipulation of oestrogen and progesterone levels. ${ }^{23}$ During pregnancy there is an increased risk of developing complications of $\mathrm{HHT}^{24} 25$ and it has been 


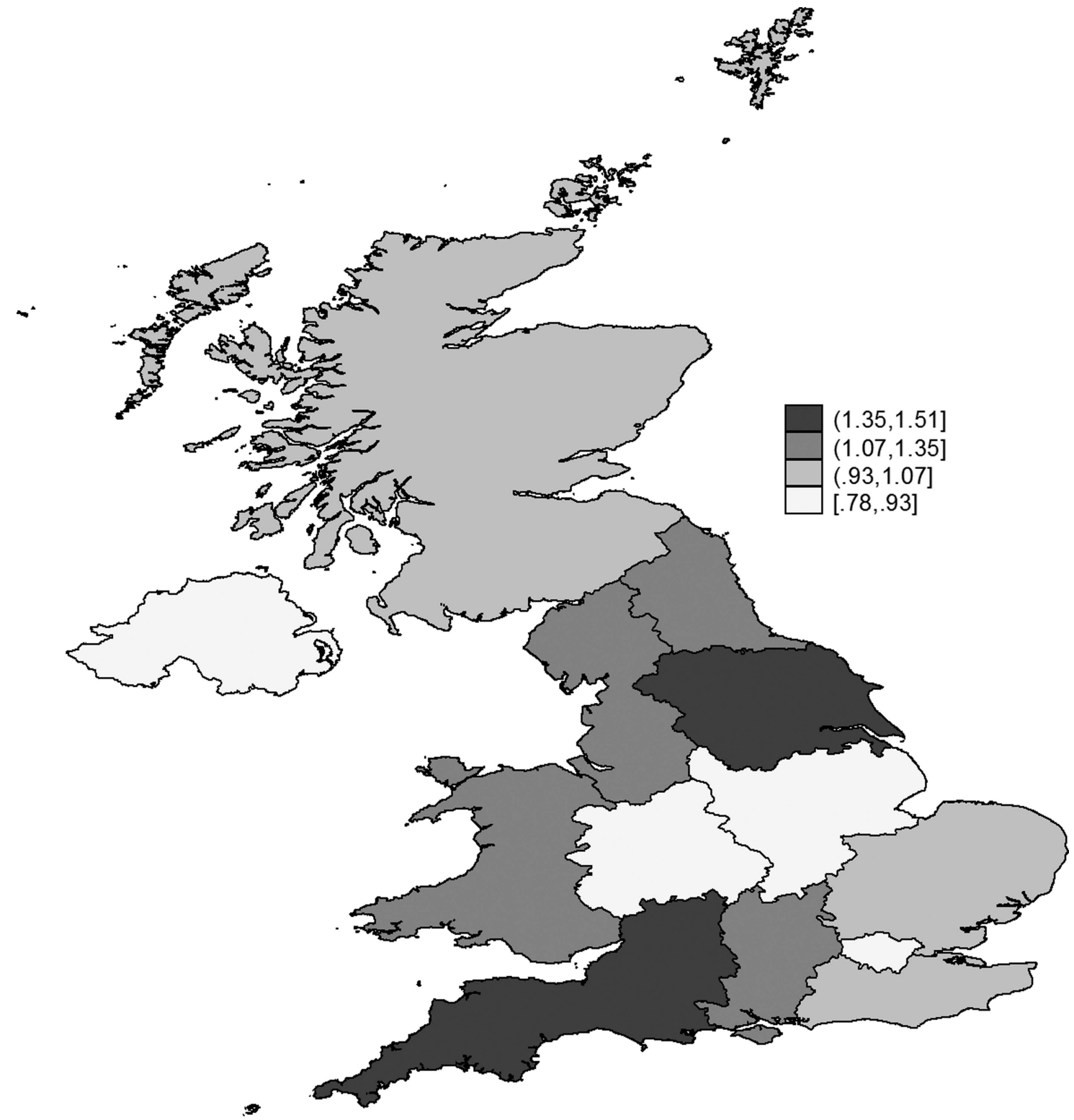

Figure 3 The crude prevalence of hereditary haemorrhagic telangiectasia (per 10000$)$ by UK health authority area (2000-2010).

suggested that this may represent a modification of the HHT vasculature by female hormones or be secondary to the haemodynamic changes of pregnancy. Clarifying whether the sex differential in diagnosis of HHT is due solely to behavioural factors or may be partly due to biological reasons is an important area for further research.

The reduced prevalence of diagnosed HHT in those from lower socioeconomic groups has multiple potential explanations which encompass controversial issues such as the proximity and quality of healthcare services provided in more deprived areas, and differentials in individuals' thresholds for accessing these services across different socioeconomic groups. It is internationally recognised that health and healthcare access inequities vary along social gradients ${ }^{26}$ and one study looking at healthseeking behaviour in those from more deprived areas with asthma found that these populations reported a higher prevalence of respiratory symptoms but had lower consultation rates for those symptoms. ${ }^{27}$ Explanations such as varying access to healthcare, differing perceptions of symptom severity or less positive views of healthcare services were postulated to explain this disparity. ${ }^{27} 28$

Finally, we observed an almost twofold difference in diagnosed prevalence throughout the UK; least common in the West Midlands and most common in the South West. A pattern of geographical variability has been seen in other studies, most notably in the landmark French paper which first identified a particularly high concentration of affected individuals in the Ain, Jura and Deux-Sevres regions of the country. ${ }^{29}$ They attributed their findings to a local founder effect when an initial new mutation had given rise to a cluster of affected individuals that then gradually moved by diffusion to involve other nearby regions. ${ }^{30}$ It is not possible to say whether our findings could represent genetic clusters of the disease in the UK or if they are the result of variations in local primary or secondary care recording practice or access to healthcare resources. Further work should try to address this as there may be regions of the UK with a disproportionate underdiagnosis of HHT, thus exposing individuals to the avoidable risk of the complications of this disease. 
Table 3 Crude prevalence rates and prevalence rate ratios (PRRs) derived from Poisson regression modelling of hereditary haemorrhagic telangiectasia prevalence using The Health Improvement Network dataset between 2000 and 2010

\begin{tabular}{|c|c|c|c|}
\hline & $\begin{array}{l}\text { Crude prevalence rates }(95 \% \mathrm{Cl}) \\
\text { per } 10000 \text { person-years }\end{array}$ & Crude PRRs $(95 \% \mathrm{Cl})$ & $\begin{array}{l}\text { Mutually adjusted } \\
\text { PRRs }(95 \% \mathrm{Cl})^{*}\end{array}$ \\
\hline \multicolumn{4}{|l|}{ Health Authority } \\
\hline West Midlands & 0.78 (0.69 to 0.88 ) & 1.01 (0.85 to 1.19$)$ & 1.00 \\
\hline East Midlands & 0.85 (0.71 to 1.00$)$ & 1.09 (0.89 to 1.34$)$ & 1.08 (0.88 to 1.33 ) \\
\hline London & 0.78 (0.69 to 0.87 ) & 1.00 & 1.13 (0.96 to 1.34 ) \\
\hline South East Coast & 1.02 (0.92 to 1.13$)$ & 1.32 (1.13 to 1.54$)$ & 1.30 (1.11 to 1.52 ) \\
\hline Northern Ireland & $0.93(0.77$ to 1.09$)$ & $1.20(0.97$ to 1.48$)$ & 1.30 (1.05 to 1.61$)$ \\
\hline East of England & 1.07 (0.95 to 1.18 ) & 1.37 (1.16 to 1.61$)$ & 1.35 (1.15 to 1.59$)$ \\
\hline Scotland & 1.07 (0.97 to 1.17 ) & 1.37 (1.18 to 1.59$)$ & 1.45 (1.25 to 1.69$)$ \\
\hline North West & 1.14 (1.03 to 1.25$)$ & $1.46(1.26$ to 1.70$)$ & 1.48 (1.27 to 1.72 ) \\
\hline South Central & 1.23 (1.13 to 1.33$)$ & 1.58 (1.37 to 1.82 ) & 1.54 (1.33 to 1.77$)$ \\
\hline Yorkshire \& Humber & 1.37 (1.18 to 1.55$)$ & 1.75 (1.46 to 2.10$)$ & 1.76 (1.46 to 2.11 ) \\
\hline Wales & 1.35 (1.20 to 1.51$)$ & 1.73 (1.47 to 2.04$)$ & 1.77 (1.50 to 2.09 ) \\
\hline North East & 1.35 (1.14 to 1.55$)$ & 1.73 (1.42 to 2.10$)$ & 1.80 (1.48 to 2.19 ) \\
\hline \multirow[t]{2}{*}{ South West } & 1.51 (1.39 to 1.63$)$ & 1.94 (1.68 to 2.23 ) & 1.86 (1.61 to 2.15 ) \\
\hline & & & $p<0.0001$ \\
\hline
\end{tabular}

*Adjusted for age, sex and Townsend score.

\section{Comparison with existing literature}

Table 4 provides a summary of the HHT prevalence estimates of different studies conducted worldwide over the last 25 years. Each study has investigated different populations using different methodologies which, in part, explains the differing results. Certain areas such as the Dutch Antilles and the Ain region of France have shown particularly high prevalence of the disease. Elsewhere, most studies indicate a prevalence between 1 and $1.6 / 10000$ (or between $1 / 6000$ and 1/10 000) and our study estimate falls within this range, although data from individuals with health insurance in the USA provide estimates as low as $1 / 33000 .{ }^{20}$ Our findings with respect to age are consistent with previous work, with the prevalence of HHT being higher in older age groups, suggesting that the disease has an age-related penetrance ${ }^{17}$ or alternatively that the likelihood of diagnosis is related to longevity. No other studies have looked at the prevalence of diagnosis by deprivation status and most studies have been restricted to a small geographical area excepting the epidemiological data from France which also show a wide variation in prevalence depending on geographical location. ${ }^{29} 3132$ Further research should consider the influence of disease severity on the diagnosed prevalence rate and its potentially confounding effect on our observations with respect to sex, socioeconomic status and geographical location.

\section{Implications}

This is the first contemporary study in a representative UK population to estimate the prevalence of HHT and suggests that it is much more common than previously thought, and similar to the prevalence seen in other countries. Assuming that the prevalence of HHT in men is the same as for women, the 'true' estimate of total prevalence would be closer to $1.28 / 10000$ or

Table 4 Summary of previous prevalence studies of hereditary haemorrhagic telangiectasia

\begin{tabular}{|c|c|c|c|c|c|c|}
\hline $\begin{array}{l}\text { Year of } \\
\text { study }\end{array}$ & $\begin{array}{l}\text { Year of } \\
\text { estimate }\end{array}$ & Authors & Study setting and methodology & $\begin{array}{l}\text { Study } \\
\text { size }\end{array}$ & $\begin{array}{l}\text { Prevalence } \\
\text { rate (per } 10000)\end{array}$ & $\begin{array}{l}\text { Prevalence } \\
\text { rate }\end{array}$ \\
\hline 2013 & 2010 & $\begin{array}{l}\text { Donaldson et al } \\
\text { (present study) }\end{array}$ & UK primary care database & 365 & 1.06 & $1 / 9400$ \\
\hline 2013 & $2005-2010$ & Grosse et a $\left.\right|^{20}$ & US health insurance database & 1203 & 0.3 & $1 / 33000$ \\
\hline 2003 & 1998 & Westermann et a $/^{15}$ & $\begin{array}{l}\text { Screening extended pedigree of previously identified cases in } \\
\text { Antilles, The Netherlands }\end{array}$ & 112 & 7.51 & $1 / 1300$ \\
\hline 2002 & 2002 & Dakeishi et al ${ }^{14}$ & $\begin{array}{l}\text { Screening extended pedigree of cases referred to tertiary centre in } \\
\text { Akita prefecture, northern Japan }\end{array}$ & 23 & 1.25 & $1 / 8000$ \\
\hline 1999 & 1995 & Kjeldsen et $a l^{6}$ & Regional patient database, Fyne county, Denmark & 73 & 1.56 & $1 / 6400$ \\
\hline 1995 & 1994 & Guttmacher et $a \beta^{33}$ & Postal questionnaire of identified cases in Vermont, USA & 34 & 0.61 & $1 / 16400$ \\
\hline 1992 & 1991 & Jessurun and Nossent ${ }^{34}$ & $\begin{array}{l}\text { Study of cases hospitalised to one centre in Leeward Islands, } \\
\text { Antilles, The Netherlands }\end{array}$ & 32 & 1.94 & $1 / 5200$ \\
\hline 1992 & 1990 & Porteous et al ${ }^{13}$ & $\begin{array}{l}\text { Postal questionnaire study of cases in Newcastle, 'Northern Region', } \\
\text { UK }\end{array}$ & 79 & 0.25 & $1 / 40000$ \\
\hline 1989 & 1989 & Bideau et $a^{29}$ & $\begin{array}{l}\text { Postal questionnaire study of cases identified by physicians in France } \\
\text { (52 departments) }\end{array}$ & 406 & 1.20 & $1 / 8300$ \\
\hline 1984 & 1983 & Plauchu and Bideau ${ }^{31}$ & $\begin{array}{l}\text { Postal questionnaire study of cases identified by physicians in Ain } \\
\text { department, France }\end{array}$ & 150 & 4.25 & $1 / 2400$ \\
\hline
\end{tabular}


$1 / 7800$ (the figure calculated for women alone). A similar approach extrapolating the 'true' prevalence from women living in the South West of the UK (the health authority with the highest crude prevalence of HHT) estimates a prevalence of 1.9/ 10000 and would equate to at least 11800 cases of HHT in a population of 62.3 million in $2010 .{ }^{35}$ The lower diagnostic rate of HHT in men and those from less affluent social backgrounds suggests a sociological role (or alternatively a biological role) in the presentation of HHT, while the previously unreported regional differences is an observation that requires validation in other datasets. Future research would ideally draw on a national rare disease database with integrated clinical information and genetic samples allowing greater understanding of the presentation of the disease, the genotype-phenotype relationship in HHT and the influences upon it of moderator genes and external environmental factors.

Acknowledgements We acknowledge Mr C Smith, Division of Epidemiology and Public Health, University of Nottingham for his assistance with data extraction for the manuscript.

Contributors JWD was involved in the study conception and design, performed the majority of the data processing and analysis and drafted the manuscript. CS retrieved the data. AWF, TMM and RBH contributed to the study design and interpretation of findings. All authors were involved in revising and approving the manuscript before submission.

Funding JD is funded jointly by a grant from the University of Nottingham and Nottingham University Hospitals NHS Trust. RBH is the GSK/BLF Chair of Respiratory Epidemiology.

Competing interests None.

Provenance and peer review Not commissioned; externally peer reviewed.

\section{REFERENCES}

1 Govani FS, Shovlin CL. Hereditary haemorrhagic telangiectasia: a clinical and scientific review. Eur J Hum Genet 2009;17:860-71.

2 Shovlin CL. Hereditary haemorrhagic telangiectasia: pathophysiology, diagnosis and treatment. Blood Rev 2010;24:203-19.

3 Cottin V, Chinet $T$, Lavole $A$, et al. Pulmonary arteriovenous malformations in hereditary hemorrhagic telangiectasia: a series of 126 patients. Medicine 2007:86:1-17.

4 Shovlin $\mathrm{CL}$, Jackson JE, Bamford KB, et al. Primary determinants of ischaemic stroke/brain abscess risks are independent of severity of pulmonary arteriovenous malformations in hereditary haemorrhagic telangiectasia. Thorax 2008;63:259-66.

5 Sabba C, Pasculli G, Suppressa P, et al. Life expectancy in patients with hereditary haemorrhagic telangiectasia. QJM 2006;99:327-34.

6 Kjeldsen AD, Vase P, Green A, et al. Hereditary haemorrhagic telangiectasia: a population-based study of prevalence and mortality in Danish patients. J Intern Med 1999;245:31-9.

7 Faughnan ME, Palda VA, Garci-Tsao G, et al. International guidelines for the diagnosis and management of hereditary haemorrhagic telangiectasia. J Med Genet 2011:48:73-87.

8 Lewis JD, Schinnar R, Bilker WB, et al. Validation studies of the health improvement network (THIN) database for pharmacoepidemiology research. Pharmacoepidemiol Drug Saf 2007;16:393-401.

9 Ruigomez AE, Martin-Merino $E$, Rodriguez LAG. Validation of ischemic cerebrovascular diagnoses in the health improvement network (THIN). Pharmacoepidemiol Drug Saf 2010;19:579-85.

10 EPIC. THIN data guide for researchers. London: EPIC 2011.

11 van Gent MWF, Post MC, Snijder RJ, et al. Real prevalence of pulmonary right-to-left shunt according to genotype in patients with hereditary hemorrhagic telangiectasia: a transthoracic contrast echocardiography study. Chest 2010;138:833-9.

12 Townsend P. Deprivation. J Soc Policy 1987:16:125-46.

13 Porteous ME, Burn J, Proctor SJ. Hereditary haemorrhagic telangiectasia: a clinical analysis. J Med Genet 1992;29:527-30.

14 Dakeishi M, Shioya T, Wada Y, et al. Genetic epidemiology of hereditary hemorrhagic telangiectasia in a local community in the northern part of Japan. Hum Mutat 2002;19:140-8.

15 Westermann CJ, Rosina AF, De Vries V, et al. The prevalence and manifestations of hereditary hemorrhagic telangiectasia in the Afro-Caribbean population of the Netherlands Antilles: a family screening. Am J Med Genet A 2003;116:324-8.

16 Nakayama M, Nawa T, Chonan T, et al. Prevalence of pulmonary arteriovenous malformations as estimated by low-dose thoracic CT screening. Intern Med 2012:51:1677-81.

17 Plauchu H, de Chadarevian JP, Bideau A, et al. Age-related clinical profile of hereditary hemorrhagic telangiectasia in an epidemiologically recruited population. Am J Med Genet 1989;32:291-7.

18 Pierruci $P$, Lenato GM, Suppressa P, et al. A long diagnostic delay in patients with hereditary haemorrhagic telangiectasia: a questionnaire-based retrospective study. Orphanet J Rare Dis 2012;7:33-46.

19 Adams J, Ryan V, White M. How accurate are Townsend deprivation scores as predictors of self-reported health? A comparison with individual level data. J Public Health 2005;27:101-6.

20 Grosse SD, Boulet SL, Grant AM, et al. The use of US health insurance data for surveillance of rare disorders: hereditary hemorrhagic telangiectasia. Genet Med 2013 Published Online First 23 May 2013 doi:10.1038/gim.2013.66.

21 Kapur N, Hunt I, Lunt M, et al. Primary care consultation predictors in men and women: a cohort study. Br J Gen Pract 2005;55:108-13.

22 Hippisley-Cox J, Vinogradova Y. Trends in consultation rates in general practice 1995/1996 to 2008/2009: Analysis of the Q Research database. Leeds: The Health and Social Care Information Centre, 1999.

23 Jameson JJ, Cave DR. Hormonal and antihormonal therapy for epistaxis in hereditary hemorrhagic telangiectasia. Laryngoscope 2004;114:705-9.

24 Shovlin CL, Winstock AR, Peters AM, et al. Medical complications of pregnancy in hereditary haemorrhagic telangiectasia. QJM 1995;88:879-87.

25 Shovlin CL, Sodhi V, McCarthy A, et al. Estimates of maternal risks of pregnancy for women with hereditary haemorrhagic telangiectasia (Osler-Weber-Rendu syndrome): suggested approach for obstetric services. BJOG 2008;115:1108-15.

26 Butler DC, Petterson S, Phillips RL, et al. Measures of social deprivation that predict health care access and need within a rational area of primary care service delivery. Health Serv Res 2012:48:539-59.

27 Trinder PM, Croft PR, Jones $\mathrm{M}$, et al. Social deprivation and patterns of consultation for respiratory symptoms: a population-based cohort study. J Epidemiol Community Health 1999;53:251-2.

28 Hart JT. The inverse care law. Lancet 1971;7696:405-12.

29 Bideau A, Plauchu H, Brunet G, et al. Epidemiological investigation of Rendu-Osler disease in France: its geographical distribution and prevalence. Population 1989;44:3-22.

30 Brunet G, Lesca G, Genin E, et al. Thirty years of research into Rendu-Osler-Weber disease in France: historical demography, population genetics and molecular biology. Population 2009;64:273-92.

31 Plauchu $\mathrm{H}$, Bideau A. Epidemiologie et constitution d'un registre de population a propros d'une concentration geographique d'une maladie hereditaire rare. Population 1984;4-5:765-86.

32 Bideau A, Brunet G, Heyer $E$, et al. An abnormal concentration of cases of RenduOsler disease in the Valserine valley of the French Jura: a genealogical and demographic study. Ann Hum Biol 1992;19:233-47.

33 Guttmacher AE, McKinnon WC, Upton MD. Hereditary hemorrhagic telangiectasia: a disorder in search of the genetics community. Am J Med Genet 1995;52: 252-3.

34 Jessurun GAJ, Nossent JC. Cerebrovascular accidents at a young age in RenduOsler-Weber disease; a survey in the Netherlands Antilles. Ned Tijdschr Geneeskd 1992;136:428-31.

35 Office for National Statistics. Annual mid-year population estimates. Newport: Office for National Statistics 2010 